\title{
Complexity, Relatedness and Uncertainty in Contemporary Social Science: A Preliminary Reflection
}

\author{
Charalambos Tsekeris* and Olga Papadopoulou** \\ *Panteion University of Social and Political Sciences, Greece, tsekeris@gmail.com \\ ** Independent Psychologist/Psychotherapist and Researcher, Greece, olgio.p@gmail.com
}

\begin{abstract}
This concise preliminary reflection seeks to offer a fresh transdisciplinary lens to comprehensively discern and evaluate the various interlinks and overlaps between theory and methodology in current social scientific thought. A brief elaboration on the metatheoretical issues of complexity, relatedness and uncertainty encourages a suitable and sustainable analytic framework for generating, developing and cultivating a more open, dialogical and critical-reflexive way of perceiving social science and the precarious social world in general.
\end{abstract}

Keywords: Complex Systems, Social Networks, Chaos Theory, Relatedness, Emergence, Uncertainty, Epistemology, Methodology, Metatheory, Social Behavior, Coopetition, Reflexivity, Agency, Relational Social Science

Acknowledgement: This reflection presents personal views of the authors. It is a modified version of a paper presented at "Dialectics" Research Seminar Series (Faculty of Political Science and Public Administration, National and Kapodistrian University of Athens), which was held March 26, 2013 in Athens, Greece.

The social world ontologically consists of complex autopoietic systems that "produce and eventually change their own structures; their self-reference applies to the production of other components as well [...] Autopoietic systems, then, are sovereign with respect to the constitution of identities and differences" (Luhmann 1990).

Our whole life is embedded within such systems, which can be roughly described as "problem-solving systems. In order to do so, they are auto- and re-creative, they create new reality and new environments" (Fuchs 2003: 47). Behind each of them, there is always a network, a diagram, which potentially gives us analytical access to system's behavior and dynamics (see Barabasi 2003). The science of complex systems, or complexity science, is a general "post-Newtonian" meta-science usually referring to human societies characterized by emergent behaviors (reflexively resulting from everyday dynamic interactions and negotiations). Social systems cannot be reduced, fragmented or dis-integrated to local agency, without losing their unique identity, signature and purposefulness.

Substantively, new levels of complexity are "accompanied by new uncertainties and the emergence of well-known global and local problems" (Nowotny 2011). Analytically, complexity is being directly opposed to both sociologism (over-emphasizing grand social theoretical models or overarching conceptual schemes, ideological processes, broader social factors, and holistic macro-structures) and psychologism (over-emphasizing mental processes, individuality, cognitive properties, and psychological factors and categories).

As R. Keith Sawyer (2007) rightly maintains, human societies are complex, non-linear and dynamical systems, and the best possible way to adequately understand them is by developing the concept of emergence. This pays attention to multiple levels of analysis (individuals, social interactions, and social groups), with a special dynamic focus on local contexts and the particular, detailed ways in which group phenomena "emerge" from daily "performative" communication processes among interacting individual members.

So, while empirical sociologists often downplay the huge importance of emergence, complexity scholars appear to tackle many substantive methodological difficulties (especially through agent-based systems). In other words, they address the problem that social statisticians conventionally use a very rigid language (which does not really interpret or explain any- 
thing!), while qualitative researchers variously describe the richness of personal experience and social settings in a highly ambivalent and non-generalizing way (Tsekeris 2009).

In addition, complexity re-energizes and re-addresses the crucial issue of agency; complex systems are inhabited by agents who are:

1. Autonomous, agreeing with themselves and claiming/performing their own projects, desires, identities, and free will and choice (the latter is what perhaps distinguishes human from non-human agents). They are also heterogeneous (either following different rules of action, or possessing different resources or properties that cause them to act differently), locally reflexive, and boundedly rational - sometimes, computationally represented as mathematical or software objects (Tsekeris 2009).

2. Interdependent, agreeing with their environment and exercising this interdependency within polymorphous, recursive and relational social networks, which inherently contain social dynamics, and are the essential sites of social role-production and co-evolutionary meaning-formation. ${ }^{1}$

3. Ceaselessly interacting under disequilibrium conditions (or conditions far from thermodynamic equilibrium), as well as under the pressures of a constantly changing environment. In a sense, "chaotic and near chaotic systems bridged the gap between macro-scales and micro-scales. Chaos was the creation of information" (Gleick 1988, 260). But chaos is not random, stochastic or probabilistic, but deterministic in the sense of "aperiodic bounded dynamics in a deterministic system with sensitive dependence on initial conditions" (Kaplan and Glass 1995, 27). ${ }^{2}$

The first agential quality amounts to the tendency for adaptiveness/internal consistency, while the second one amounts to the tendency for connectedness/social conformity (Bednar et al. 2010). ${ }^{3}$ These two tendencies are the intrinsic microfoundations of social behavior and pertain to the fundamental level of social behavior and dynamics: relatedness (Spinelli 2007), or social interaction (Katerelos and Koulouris 2004).

Relational thinking traditionally implies that "the scientific concepts no longer appear as imitations of thing-like existences, but as symbols representing orders and functional links within reality" (Cassirer 1906/1971, 3). The so-called "anticategorical imperative" (Emirbayer and Goodwin 1994, 1414) actively rejects explanations of "social behavior as the result of individuals' common possession of attributes and norms rather than as the result of their involvement in structural social relations" (Wellman 1983, 165). ${ }^{4}$

\footnotetext{
${ }^{1}$ Many scholars primarily look at social networks as a distinguished form of sociability (see e.g. Holton 2005).

${ }^{2}$ Chaos theory was firstly coined by the American mathematician and meteorologist Edward Lorenz (1963), but widely communicated to the public by James Gleick's best-seller Chaos: Making a New Science, nearly two decades later (Gleick 1987). In the mid-1980s, the Santa Fe Institute (www.santafe.edu) was established to further organize and develop systematic inquiry into complex adaptive systems (CAS).

${ }^{3}$ For Bednar et al. $(2010,412,416)$, individual members within a specific community "conform their behavior to match one another's, and also that there is some relationship that ties their behaviors and beliefs together from one activity or domain to the next, creating consistency across behaviors ... empirical evidence shows that individuals tend toward both consistency and conformity. Note that we do not take consistency and conformity to be hard and fast rules but, rather, emphasize that they are two general forces that guide human behavior. Momentto-moment, individuals can be as unpredictable in their behavior as they might be arbitrary in whom they imitate, but on the whole, they tend to be consistent and coordinate with others ... these two simple pressures alone can generate the macro-observation of groups that are distinct from one another, that possess meaningful culture signatures, and that are characterized by persistent within-culture diversity". In this methodological context, an agent permanently oscillates between a "social" equilibrium and an "internal-psychological" equilibrium. In some sense, each time agents "attain" social equilibrium (consensus), the psychological equilibrium mechanism destabilizes and differentiates them into one of the previously socially stable dimensions. Of course, being desynchronized exhibits the need for social coordination once again. This is a perpetual systemic motion that can accurately demonstrate different types of dynamics (see Katerelos and Koulouris 2004).

${ }^{4}$ Mustafa Emirbayer's (1997) famous "manifesto for a relational sociology", heavily drawing upon pragmatist, linguistic and interactionist philosophies, as well as upon historical and network analysis, arguably promotes a non-substantive ontological conceptualization of our social world, where human relations tend to dynamically evolve, shift and change.
} 
Relational conceptions, such as networks, flows, fields, figurations, discursive formations, and so on, have increasingly gained widespread currency in contemporary social thought (Depelteau and Powell 2013). Social science now becomes relational and "mobile", in order to efficiently respond to growing issues of global transformation, complexity and disorder, or to adequately address the increasingly "heterogeneous, uneven and unpredictable mobilities of people, information, objects, money, images and risks, that move chaotically across regions in strikingly faster and unpredictable shapes" (Urry 2000,194).

Nevertheless, chaos/complexity, non-linearity and unpredictability paradoxically emerge out of order and recurrence. As John Urry $(2000,196)$ rightly puts it, complex change may not necessarily involve revolutionary "agents actually seeking to change that world. The agents may simply keep carrying out the same recurrent actions or what they conceive to be the same actions. But it is through iteration over time that they may generate unexpected, unpredictable and chaotic outcomes, often the very opposite of what the human agents involved may seek to realize".

In the sociological spirit of Giddens's (1984) structuration theory, ${ }^{5}$ human agents often desire to keep things under control and maintain order, but may eventually produce large-scale societal transformation through unforeseen, unanticipated and unintended effects. Sociological issues of reflexivity and social change are now radically contextualized (rather than necessarily linked to grand emancipatory projects), as demonstrated in Urry's chaos-friendly reinterpretation of Marxist theory: "Marx's inability to predict social revolution can be regarded by contemporary theory as comprehensible since relatively small perturbations in the system can produce a very different branching of the social world from what he envisaged a century or so ago" (Urry 2000, 197).

Social inquiry then, instead of naively starting from a grand conception of the "totality", becomes more modest, more contextual, and more dialogical; it must necessarily involve tackling specific issues of understanding and analysis in a more relational and inclusive account, with a strong orientation towards the real world and concrete problems of public relevance. In this regard, reflexive scholars should always refer to the meanings of actors and their inherent capacity to purposefully reformulate meanings as a necessary condition of the adequacy of any theoretical account (see Holmwood 2003).

Reflexive social science must eventually be conceived as a fruitful dynamical form of joint inter-relational dialogue (between equal partners), where both professional social scientists and social agents or "participants" (as lay social scientists) have indeed a mutual interest in explanatory undertakings (Holmwood 2003). ${ }^{6}$ Most importantly, it is actually this "mutual interest" that makes the dialogical activity possible, meaningful and critical (see Tsekeris 2012).

Following Ernesto Spinelli $(2010,102)$, horizontalization prevails here to avoid placing any holistic unsubstantiated (top-down) hierarchies of significance or importance upon the participant's statements of lived experience. ${ }^{7}$ The researcher and the participant exist in an "endless dance of co-emergence" (Waldrop 1992, 75), a novel uncertain condition of epistemic coopetition: "co-operation with one another not because we have eradicated the conflict between us, but rather because our attempt at 'being for' one another arises through the mutual recognition of the inevitable conflict between us" (Spinelli 2004, 62).

The inherently shared, complex, processual and networked character of social reality (at any level, micro or macro) directly and inevitably results in uncertainty, a general essential condition that becomes reflexive in the analytical context of "radical uncertainty" accounts of sociologists (Woolgar 1988) and psychologists (Spinelli 2007). Embracing chaos and uncer-

\footnotetext{
${ }^{5}$ According to Anthony Giddens (1976: 102), "all reproduction is necessarily production, however: and the seed of change is there in every act which contributes towards the reproduction of any 'ordered' form of social life".

${ }^{6}$ Of course, this does not assume the mutual validity of accounts, but their equal corrigibility.

7 This comes in direct contrast to any substantialist top-down procedure, which would inevitably pre-suppose emerging complexity as a starting point, finally leading to a circular argument - a reflexive duplication, or a vicious analytical circle (see Pels 2000).
} 
tainty with courage and willingness, moving between realism and optimism, could possibly pertain to living our life with full engagement, creativity and critical spirit. ${ }^{8}$

Uncertainty, conflict (or coopetition) and relatedness (or inter-relation) are thus key analytical and substantive principles (Spinelli 2007, 2010), which productively find each other in the indispensable level of meaningful social interaction - that is, the fundamental level of social behavior and societal dynamics (Katerelos and Koulouris 2004). It is perhaps at this transdisciplinary (perhaps, non-disciplinary) epistemological crossroad that the relational approach fruitfully meets philosophy (mostly, transcendental realism and general social theory, with an existential and phenomenological emphasis), social science, and meta-science (chaos/complexity and self-organization theory), with a strong critical-reflexive and constructive impetus.

The emergent "relational" paradigm shift in social science (see e.g. Depelteau and Powell 2013) potentially provokes a creative redemption of Karl Mannheim's magic triangle: ontology, epistemology and ethics (critique). Hence, qualitative complexity "not only serves as a basis for demarcating the distinctive character of the social as an object of knowledge, but also allows for the reflexive, knowledge informed, reconstitution of the social order" (Byrne 1998, 51). Complexity's "social agents" obtain an irreducible reflexive capacity to view that the whole is greater than the sum of its parts and therefore to critically discuss different versions of reality, to synenergetically meta-theorize, and to empathically see themselves through the eyes of the other. The latter recovers the (relational) normative or moral dimension of the essential complexity of our social world.

\section{References}

Archer, Margaret. 2003. Structure, Agency and the Internal Conversation. Cambridge: Cambridge University Press.

Barabasi, Albert-László. 2003. Linked: How Everything Is Connected to Everything Else and What It Means for Business, Science, and Everyday Life. New York: Plume.

Bednar, Jenna, Aaron Bramson, Andrea Jones-Rooy and Scott Page. 2010. Emergent Cultural Signatures and Persistent Diversity: A Model of Conformity and Consistency. Rationality and Society 22 (4): 407-444.

Byrne, David. 1998. Complexity Theory and the Social Sciences: An Introduction. London: Routledge.

Cassirer, Ernst. 1906/1971. Das Erkenntnisproblem in der Philosophie und Wissenschaft der Neuere Zeit. Darmstadt: Wissenschaftliche Buchgesellschaft.

Emirbayer, Mustafa. 1997. Manifesto for a Relational Sociology. American Journal of Sociology 103: 281-317.

Emirbayer, Mustafa and Jeff Goodwin. 1994. Network Analysis, Culture, and the Problem of Agency. American Journal of Sociology 99: 1411-1454.

Dépelteau, Francois and Christopher Powell, eds. 2013. Relational Sociology: From Project to Paradigm. New York: Palgrave.

Fuchs, Christian. 2003. Co-Operation and Self-Organization. tripleC - Cognition, Communication, Cooperation: Open Access Journal for a Global Sustainable Information Society 1 (1): 1-52. Accessed October 5, 2013. http://www.triple-c.at/index.php/tripleC/article/view/2/0

Giddens, Anthony. 1976. New Rules of Sociological Method. London: Hutchinson.

Giddens, Anthony. 1984. The Constitution of Society: Outline of the Theory of Structuration. Cambridge: Polity Press.

Gleick, James. 1988. Chaos: Making a New Science. New York: Penguin.

Holmwood, John. 2003. Problems of Reflexivity: 'Dialogic' Social Inquiry and the Displacement of Explanation. Teorie Vedy, X11/XXV (4): 7-58.

Holton, Robert. 2005. Network Discourses: Proliferation, Critique and Synthesis. Global Networks 5: 209-15.

Kaplan, Daniel and Leon Glass. 1995. Understanding Nonlinear Dynamics. New York: Oxford University Press.

\footnotetext{
${ }^{8}$ In this relational context, chaos/uncertainty is neither avoidable nor destructive; instead, it can be imaginatively theorised as a unique opportunity and capacity to critically think, co-act and change, as well as something we should responsibly accept, acknowledge, embrace, celebrate and live with (Tsekeris 2010; Tsekeris and Koskinas 2010).
} 
Lorenz, Edward. 1963. Deterministic, Non-Periodic Flow. Journal of Atmospheric Sciences 82: 985992.

Luhmann, Niklas. 1990. The Cognitive Program of Constructivism and a Reality that Remains Unknown. In Self-Organization: Portrait of a Scientific Revolution, edited by Wolfgang Krohn, Günther Küppers and Helga Nowotny. Dordrecht: Kluwer.

Nowotny, Helga. 2011. Producing Sociology in Today's Unequal World. Global Dialogue 2 (2). Accessed October 1, 2013. http://www.isa-sociology.org/global-dialogue/2011/11/producingsociology-in-today\%E2\%80\%99s-unequal-world/

Sawyer, Keith. 2007. Social Emergence: Societies as Complex Systems. New York: Cambridge University Press.

Spinelli, Ernesto. 2004. Hell Is Other People: A Sartrean View of Conflict Resolution. International Journal of Existential Psychology and Psychotherapy 1 (1): 56-65.

Spinelli, Ernesto. 2007. Practising Existential Psychotherapy: The Relational World. London, UK: Sage.

Spinelli, Ernesto. 2010. Existential Coaching. In The Complete Handbook of Coaching, edited by Elaine Cox, Tatiana Bachkirova and David Clutterbuck. London: Sage.

Tsekeris, Charalambos. 2009. Advances in Understanding Human Complex Systems. Australian Journal of Basic and Applied Sciences 3 (4): 4040-4045.

Tsekeris, Charalambos. 2010. Chaos and Unpredictability in Social Thought: General Considerations and Perspectives. Sociologija. Mintis ir veiksmas 27 (2): 34-47.

Tsekeris, Charalambos and Konstantinos Koskinas. 2010. A "Weak" Reflection on Unpredictability and Social Theory. tripleC - Cognition, Communication, Co-operation: Open Access Journal for a Global Sustainable Information Society 8 (1): 36-42. Accessed October 3, 2013. http://www.triplec.at/index.php/tripleC/article/viewArticle/183

Pels, Dick. 2000. Reflexivity: One Step Up. Theory, Culture \& Society 17 (3): 1-25.

Tsekeris, Charalambos. 2012. Advances in Reflexive Sociology: Theory, Agency and Dialogical Inquiry. Italian Sociological Review 2 (2): 66-75.

Urry, John. 2000. Mobile Sociology. British Journal of Sociology 51 (1): 185-201.

Waldrop, Mitchell. 1992. Complexity: The Emerging Science at the Edge of Order and Chaos. New York: Simon \& Schuster.

Wellman, Barry. 1983. Network Analysis: Some Basic Principles. In Sociological Theory, edited by Randall Collins. San Francisco: Jossey-Bass.

Woolgar, Steve. 1988. Science: The Very Idea. London: Tavistock.

\section{About the Authors}

Charalambos Tsekeris

graduated with Distinction from Brunel University (West London, UK) and earned his doctoral degree in Reflexivity from Athens Panteion University (Department of Sociology). He is Member of the Hellenic Sociological Society, Visitor at the Hellenic Naval Staff and Command College, and Senior Researcher at the Lab of Virtual Reality, Internet Research \& E-Learning, Department of Psychology, Panteion University of Social and Political Sciences, Athens, Greece. His research interests involve chaos theory, human complex systems, psychosocial studies, epistemology, and sociological metatheory.

Olga Papadopoulou

studied Psychology, Psychotherapy and Counselling at the American College of Thessaloniki, Greece, City University London, UK, and the University of Greenwich, London, UK. She is an independent practitioner, psychotherapist/counsellor and researcher in Greece, and a member of the British Association for Counselling and Psychotherapy (BACP), UK. Her research interests involve counselling psychology, integrative therapy, existential psychotherapy, existential theory and philosophy, phenomenology, reflexive methods in psychological theory and practice, psychological metatheory, epistemology, and cognitive neuroscience. 